\title{
EL GRAN CATHARRO DE 1580 ¿GRIPE O PERTUSSIS?*
}

\section{Ramón Camaño Puig}

Universidad de Valencia

\section{Mariano Barriendos Vallvé}

Universidad de Barcelona

\section{Francisco Faus Gabandé}

Universidad de Valencia

\section{RESUMEN}

El Gran Catharro (1580) es considerado como la primera epidemia de gripe. El análisis conjunto de los datos contenidos en diferentes testimonios, suscita dudas respecto a que se tratara de una epidemia de gripe y apoyan la posibilidad de que se tratara de una de tos ferina.

PALABRAS CLAVE: Gran Catharro de 1580, gripe, tos ferina.

\section{SUMMARY}

The gran Catharro (1580) is considered the first influenza epidemic. The analysis of various testimonies of the time may offer some doubts about whether or not it was so; and data strongly support that it was a pertussis epidemic.

KEY WORDS: Gran Catharro (1580), influenza, pertussis epidemic.

\section{INTRODUCCIÓN}

La utilización de vacunas contra la Bordetella Pertussis, bacteria productora de la tos ferina, ha producido en las últimas décadas una reducción espectacular de su morbilidad y mortalidad, fundamentalmente en los países industrializados. La tos ferina pasa en la historia por ser una enfermedad infantil muy contagiosa,

* Los autores desean agradecer al Prof. Josep Lluis Barona Vilar la lectura y comentarios realizados a este artículo. 
en la que prácticamente el $100 \%$ de los niños receptivos de un mismo foco contraen el mal, después de haber estado en contacto con el sujeto infeccioso ${ }^{1}$. Y de hecho la mayoría de infecciones se ven en niños menores de un año.

La tos ferina tiene su agente causal en la Bordetella Pertussis, bacteria que produce la enfermedad en humanos y para la cual no se conoce ningún otro reservorio animal o ambiental. Su incidencia, morbilidad y mortalidad se vieron reducidas drásticamente tras la introducción de la vacuna en 1949. Pero la tos ferina sigue siendo endémica en todo el mundo y puede afectar cada año a más de 60 millones de personas, pudiendo matar alrededor de 360.000 niños de los cuales más de dos tercios son lactantes ${ }^{2}$.

Los primeros ensayos llevados a cabo de una vacuna tuvieron lugar en las islas Feroe, durante los años 1923 y 1924, procediéndose a realizar posteriormente otros ensayos sobre varias vacunas en los Estados Unidos e Inglaterra. En el comienzo de la vacunación en USA, en 1948, y su generalización a partir de 1953, la vacuna contenía bacterias enteras inactivadas; se procedió a su introducción posterior en un gran número de países industrializados. Todo esto se pudo realizar gracias a los trabajos llevados a cabo en 1906 por Bordet y Gengou $^{3}$, mediante los cuales se procedió a aislar la bacteria Bordetella Pertussis. Más tarde los trabajos de Eldering y Kendrick 4 aislaron la Bordetella Parapertussis, responsable del 5\% de casos de tos ferina. En los últimos años, estamos asistiendo a un aumento de los casos en niños y adultos, aspecto que se puede atribuir a la disminución de la inmunidad, que ocurre con el paso del tiempo, disminución que se produce incluso en las personas vacunadas ${ }^{5}$.

Nuestra preocupación por la climatología - y su posible impacto en la aparición y desaparición de enfermedades infecciosas - nos llevó a concentrar nuestra atención en una situación específica como fue el Gran Catharro de 1580. Los datos que fueron apareciendo, y su análisis comparativo, nos indujeron a pensar que la identificación de este proceso como una gripe, no estaba tan clara. En este sentido, el análisis de aspectos relacionados con la sintomatología descrita en diversos textos, de aspectos relacionados con la climatolo-

1 Etiemble, J., dir. (1999), Vaccinations: actualités et perspectives, París, INSERM Expertise Collective, p. 349.

2 Etiemble (1999), p. 13.

3 Plotkin S. A.; y OrensteIn W.A. (1999), Vaccines, Filadelfia, W. B. Saunders, $3^{\text {a }}$ ed.

4 Eyquem, A.; Alouf, J.; y ChippauX, A. (1998), Manuel des vaccinations et d'immunoprévention. Padua, Piccin Nuova Libraria.

5 He, Q.; Viljanen, M. K.; y Arvilommi, H. (1998), «Whopping Cough Caused by Bordetella Pertussis y Bordetella Parapertussis in a Inmunized Population», Journal of American Medical Association, 280, 635-637. 
gía y cuestiones relacionadas con la inmunidad, pueden ser ilustrativos para analizar la posible evolución que se puede producir en un futuro.

El Gran Catharro es reconocido como la primera epidemia de gripe de diseminación global por múltiples autores ${ }^{6}$, aunque nuestra búsqueda no ha proporcionado estudios históricos o diagnósticos específicos respecto de la evolución de esta epidemia de gripe. Dicha epidemia comenzó en Asia y de allí pasó a Europa y América. Casi toda Europa fue afectada en seis semanas, y se dice que sólo el veinte por ciento de la población escapó de la enfermedad.

Los criterios de definición de las enfermedades infecciosas durante el periodo pre-laboratorio de la medicina, anterior a la primera mitad del siglo XIX, y los actuales de la medicina contemporánea son muy diferentes. Por ello nuestro análisis debe de ser entendido manteniendo las correspondientes salvaguardas y cautelas ${ }^{7}$, que deben plantearse, a la hora de hablar de un diagnóstico retrospectivo, tal y como Cunningham ${ }^{8}$ reconoce, y ha sido recogido por Arrizabalaga ${ }^{9}$. Con anterioridad, los diagnósticos sólo podían ser realizados a partir de los síntomas y el curso clínico, después del desarrollo del laboratorio los criterios han cambiado, lo que nos lleva tal y como dice Cunningham a que seamos incapaces de afirmar que, procesos que han sido definidos actualmente sean iguales o similares a otros anteriores, siendo mayor la dificultad cuanto mayor es el salto temporal efectuado. Por otra parte Grmek ${ }^{10}$ planteó, que la identificación de enfermedades del pasado en términos nosológicos actuales es factible siempre que se disponga de fuentes y materiales apropiados. En última instancia, hay que reconocer como dice Arrizabalaga ${ }^{11}$, que este tipo de construcciones históricas se enfrentan a la imposibilidad de reproducir las condiciones biológicas y ecológicas, fenómeno que es inconce-

6 Pyle, G. (1986), The Difussion of Influenza: Patterns and Paradigms, Nueva Jersey, Rowan and Littlefield; Beveridge, W. (1991), «The Chronicle of Influenza Epidemics», Historical and Philosophic Life Sciences, 13, 223-235; Potter, C. (2001), «A History of Influenza», Journal of Applied Microbiology, 91, 572-579.

7 Cipolla, C. M. (1993), Contra un enemigo mortal e invisible, Barcelona, Crítica.

8 Cunningham, A. (1991), «Transforming Plague: the Laboratory and the Identity of Infectious Disease», Dinamys, XI, 73-117.

9 Arrizabalaga, J. (1993), «La identificación de las causas de muerte en la Europa pre-industrial: algunas consideraciones historiográficas», Boletín de la Asociación de Demografia Histórica, XI (3), 23-47.

10 GrMeK, M. D. (1983), Les maladies à l'aube de la civilisation occidentale. Recherches sur la réalité pathologique dans le monde grec préhistorique, archaïque et classique, París, Payot.

11 Arrizabalaga (1993), p. 42. 
bible actualmente por razones técnicas y éticas que serían, en todo caso, la prueba definitiva que las validase o refutase.

Con el estudio de casos, en la historia, podemos obtener algunas ideas, de lo que podría producirse en una situación de déficit de inmunidad, por pérdida de ella o disminución de ésta ante una ausencia prolongada de contacto con la bacteria. Situación que si se baja la guardia, podría reproducirse en algún momento. Sin ser alarmistas, en 1975 en los Estados Unidos, se comunicaron algo más de 1500 casos, y en 1998 se había pasado a casi 8000, cifras que con toda seguridad subestiman la verdadera incidencia de la enfermedad ${ }^{12}$.

En nuestro país, desde 1965, existe un programa de vacunación con difteria, tétanos y tos ferina, pero a pesar de ser uno de los países con mayor cobertura vacunal (superior al 95\%), recientemente se ha comunicado en el marco del II Congreso de la Asociación Española de Vacunología (AEV), celebrado en las Palmas de Gran Canaria, que en uno de cada cuatro casos de tos ferina en niños menores de un año, la fuente principal de la infección es un adulto que vive con el bebé, e incluso, se han producido brotes epidémicos, tales como el ocurrido en la Provincia de Castellón en el año 200213.Si bien es cierto que ha transcurrido mucho tiempo desde que tuvieran lugar los eventos del Gran Catharro de 1580, todos estos datos pueden, en cierto modo, proporcionar información que nos permita enfrentarnos, de distinta manera, a los múltiples casos de tos que en algún momento se pueden ver actualmente en la clínica. Casos con una evolución similar a un catarro y que, en realidad, pudiera ser que se estuviera tratando de una tos ferina. Couzigou y Flahault ${ }^{14}$ plantean que, incluso entre médicos con un particular compromiso con los temas de salud pública, la tos ferina no está claramente considerada como causa de tos persistente en adultos; la posibilidad de este diagnóstico sólo valdría en los casos donde los síntomas son realmente severos.

En este sentido, se ha procedido a realizar el análisis de testimonios relacionados con el Gran Catharro que tuvo lugar alrededor de 1580 y que se extendió a lo largo y ancho del sur de Europa. A este fin se han consultado diferentes archivos, entre ellos los históricos de los Ayuntamientos de Barce-

12 Murray, P. R.; Rosenthal, K. S.; Kabayasi, G. S., y Pfaller, M. A. (2002), Microbiología médica, Madrid, Mosby.

13 Escorihuela, R., y BARAJAS, M. V. (2002), "Tos ferina un problema emergente», Revista de Salud Pública, 76, 267-270.

14 Couzigou, C. y Flahault, A. (2003), «Is Pertussis Being Considered as a Cause of Persistent Cough among Adults?», European Journal of Epidemiology, 18, 1.013-1.015. 
lona y Valencia y el de la Diputación Provincial de Valencia, el cual contiene los fondos del Hospital General valenciano.

A partir de los archivos y de diferentes publicaciones independientes se han compilado testimonios de la época del Gran Catharro; realizándose, a continuación, el cotejo y análisis de los datos contenidos en los diferentes testimonios con los del síndrome clínico de la tos ferina y de la gripe, y a partir de ahí, proceder hasta donde ha sido posible a un diagnóstico diferencial. Aunque el Gran Catharro de 1580 había sido catalogado en algunas publicaciones como gripe, hay determinados datos que inducen a pensar que no se trataba de tal.

\section{LA INFECCIÓN}

La infección a causa de la Bordetella Pertussis se inicia con la inhalación de la bacteria en forma de aerosol, y la adherencia de ésta a las células epiteliales ciliadas del tracto respiratorio y su posterior crecimiento. Transcurridos entre siete y diez días de incubación, se suceden tres etapas; la primera o catarral, con sintomatología que tal y como su nombre indica, es parecida a un catarro común, con rinorrea serosa, estornudos, malestar general, anorexia y febrícula, siendo este el momento de mayor nivel en la proliferación de la bacteria y por lo tanto de máximas posibilidades de transmisión.

Después de una o dos semanas, aparece la fase paroxística o períodos de tos repetida seguidas de un estridor respiratorio, en la cual las células ciliadas son expulsadas del árbol respiratorio e incrementándose la producción de moco, el cual, es en parte responsable de producir la obstrucción del flujo aéreo. La fase paroxística acaba generalmente con vómitos y estado de agotamiento. Después de dos a cuatro semanas la enfermedad entra en la tercera y última etapa o de convalecencia ${ }^{15}$.

\section{REFERENCIAS ANTIGUAS}

Entre las diferentes referencias que hemos podido analizar, relacionadas con el Gran Catharro de 1580, encontramos un testimonio fiable e independiente respecto de las autoridades municipales del momento, en la ciudad de Barcelona, el padre Pere Gil, el cual, aunque contemporáneo del contagio, redactó su

15 Murray, Rosenthal, Kabayasi y Pfaller (2002). 
testimonio en un libro veinte años después ${ }^{16}$. Los numerosos contactos con jesuitas, incluidos en su escrito —en donde relata la extensión de la epidemia aportando datos incluso de América-, dan fiabilidad al testimonio:

Lo any 1580 contengue aquell gran catharro tan nomenar; que fou general en tot lo mon; y resultà de infectio de ayre. Comença desde las parts Septentrionals, y poc a poc per sos passos contats passà per Italia, y per las Islas [Córcega, Cerdeña y Baleares], y per França; y entra en lo Agost per Cathalunya, y corregue per tota España, y passà fins a la India Occidental.

Por otro lado Despalau ${ }^{17}$, había relatado que:

A 4. de agost any 1580. Vingue una manera de catarro en barcelona que donaua febra y tos y algunes dolos que tota la yent de barc. ne pasa y sen moriren molt y vingue dit catarro del final del camp ol rey de fransa. y lo qual feu estrago molt gran ali a quaranta galeres que aguardavan los soldats de flandes los quals avien de venir a espaya y la guerra de portugal: feu tambe grandisim dany a perpinya y girona y casi per tota catalluya.

E indicaba algunos síntomas, pero poniendo el énfasis en los daños, incluso militares, que pudo provocar la epidemia. Otro aspecto a destacar fueron las referencias climatológicas que este autor realizó ${ }^{18}$ :

A 10 de setembre de .1580. entrada de nit aparegue en ves la tramuntana Un nuvol tot vermell ab algunes vies blanques.quese anaue disminuint y en sec qe aumentaue y de aquestos nuvolls sen veren tres sa matexa nit sols los altros dos al llevant laSu .y lo altra enves lo mityorn: anse fets grans yudicis en barcelona y la yent romanguer molt espantada.

Referencias climatológicas que eran coincidentes con un contexto climático tremendamente anómalo: en aquellos años, se empezaba a producir una oscilación climática con incremento de los episodios de lluvia extremos, temporales, grandes nevadas y olas de frío. Era la primera manifestación dura, de lo que desde mediados del siglo XIV estaba ocurriendo en latitudes más altas (Noruega, Islandia, Groenlandia) y que conocemos como miniglaciación (Lit-

16 Iglesies, J. (1949), Pere Gil i la seva Geografia de Catalunya, Barcelona, Obispado de Barcelona.

17 Despalau, F. (1580), Memories importants (Barcelona: Biblioteca de Catalunya, ms. 510), pp. 78-79.

18 Despalau (1580). 
tle Ice Age ó Kleine Eiszeit). Situación con diferentes pulsos y «pausas» que se prolongó hasta mediados del siglo $\mathrm{XIX}^{19}$. Aunque este no es el caso que nos ocupa, ya que, como se puede apreciar en el siguiente comentario ${ }^{20}$

fonc servit nostre senyor per nostres culpes que del dia de nostra senyora de agost fins lo dia de St. Roch caygueren malalts en la present Ciutat de Barcelona mes de vint Milia persones (que suponía para la época un 80/90 \% de la población) malaltes de una constitució de ayre calent, lo qual invadia a tots sense ningun discrim y cayent malalt hu en una casa tots ne passaven.

La epidemia comenzó en un momento de aires de poniente, lo que hace suponer temperaturas altas. Los datos fueron registrados siguiendo la tradición galénica medieval, reconociendo en primer lugar, y a nivel posiblemente remoto, la intervención divina e incorporando el concepto de culpa en su generación. En un segundo nivel o intermedio, el aire se consideró alterado, y productor de una reacción hostil en cuerpos predispuestos, ya que acarreaba un agente nocivo o tenía sus cualidades alteradas, y por último, a nivel próximo, tal y como se puede apreciar en las citas que aparecerán a continuación, la correspondiente alteración humoral que produce la sintomatología en los afectados ${ }^{21}$.

Hay una cierta discrepancia, entre los autores citados, a la hora de plantear el comienzo de la epidemia, encontrándose diferencias de prácticamente hasta dos semanas entre el primero de Pere Gil y el último. Despalau ${ }^{22}$ habla de que la epidemia comenzó el 4 de agosto y el Manual de Novells Ardits asigna el comienzo de la epidemia al día de Nuestra Señora, con lo que se puede suponer que está hablando del 15 de agosto. Estas discrepancias no son extrañas, dadas las dificultades del momento para realizar una adecuada recogida de datos, y por lo tanto, para la obtención de un cierto nivel adecuado de exactitud. Por otra parte, Pere Gil nos habló de la epidemia habiendo transcurrido

19 BARriendos, M. (1997), «Climatic Variations in the Iberian Peninsula During the Late Maunder Minimum (AD 1675-1715): an Analysis of Data from Rogation Ceremonies», The Holocene, 7 (1), 105-111. Y BARRIENDOS (1999), «La climatología histórica en el marco geográfico de la antigua monarquía hispana», Scripta Nova. Revista Electrónica de Geografía Ciencias Sociales, Universidad de Barcelona, n 53, 1 de diciembre de 1999.

20 Archivo Histórico Municipal de Barcelona, Manual de Novells Ardits, vol. 5, 15621587 , p. 248; 15 a 18 de agosto de 1580.

21 NutTon, V. (1990), «The Reception of Fracastoro's 'Theory of Contagion': the Seed that Fell Among Thorns?», Osiris, 6, 196-234.

22 Despalau (1580). 
veinte años, lo que hace, que no sea extraña su falta de coincidencia. No obstante su testimonio se ubica en un adecuado punto medio ${ }^{23}$.

Conforme per verdadera relacio demolts se entengue. En Cathaluña comença, cerca dels .10. /o/ .12. de Agost, y dura cerca de un mes y mitg fins los ultims de Setembre. Yo estava en Barcelona, y me certificaren molts, que casi tots los ossells de gabia de Barcelona moriren. Pardals ni ossells no volaren tot aquell temps ni enla ciutat ni enlo pla de Barcelona. Adverti que de mil persones, apenas ne campava una, que no tingues catarro.

Respecto a la sintomatología referida por los distintos autores, se ha querido poner primero la más reciente en el tiempo, ya que en ésta el padre Pere Gil procede a realizar una descripción previa e introductoria, sin demasiada concreción, debido posiblemente a la lejanía de su descripción con respecto al momento del suceso ${ }^{24}$ :

Donava un dolor de cap cruelissim. Causava febre, y à alguns li durava la febre un dia natural: als de mes dos, y tres: y à alguns fins à .8. y deu dies. Era tan resia la febre que pareyxia pestilential: y della restavan las personas tan debilitadas, que havian menester molts dies per la convalescencia. Curayanlo los metges ab sola dieta, sens sagnia; y la dieta no era molta: y donavan bons aliments de caldos sustanciosos, y medicaments per ablanir y arrancar.

Por otra parte, la descripción que se realiza en el Manual de Novells Ardits es la siguiente ${ }^{25}$ :

gran dolor de cap, gran difficultat de ale y portave una veu ronca y apres una orror de fret y apres febra y apres tos mol gran, la qual los primers dies apparie la tos era seca sense arrencar res, y apres passat lo sete o quatorze scopien molt del pit, y mes en tot lo progres que staven malalts tenien una llassitut y desgana de tot lo cors y debilitacio molt gran de virtut y desgana molt gran de menjar qualsevol vianda, y tenien molt gran vigilia per causa de la tos, y molts en la fi de la malaltia tenien cambres y molts suaven, la qual evaquacio de suor a molts curave y feu molta utilitat.

Es una descripción bastante pormenorizada, basada en el relato próximo y fundamentado en la experiencia, que se ha obtenido con la visión de muchos

\footnotetext{
23 IGLESIES (1949).

24 IGLESIES (1949).

25 Manual de Novells Ardits (1580), p. 248.
} 
casos similares. Al ser cronológica permite realizar el seguimiento y evolución del conjunto de los casos. Es esta descripción, la que nos hace dudar de la afirmación de que se pudiera tratar de una gripe, tal y como en múltiples escritos se ha venido recogiendo. Al comienzo de este apartado, se realizó la descripción de la sintomatología de la tos ferina y la descripción que encontramos en el Manual de Novells Ardits, parece reflejar de manera clara las tres fases por las que transcurre esta enfermedad.

\section{DUDAS}

Por otra parte, los datos que permiten introducir dudas de que este brote epidémico pudiera ser considerado como gripe, son los siguientes. En primer lugar, la duración de la clínica, ya que la duración estimada de la gripe es de siete a diez días máximo, con posibles complicaciones respiratorias por infecciones bacterianas. Siendo la aparición del clásico síndrome gripal bastante temprana, entre los dos y los cuatro días y extraño que todos los afectados sufran de complicaciones y/o infección respiratoria. Y en segundo lugar, es un brote que aparece en verano, durante los meses de agosto y septiembre y con temperaturas altas, tal y como describe ese Manual.

En la descripción que encontramos en el Manual, la sintomatología se alarga hasta los catorce días y más, con el correspondiente período paroxístico y la posterior convalecencia, «los primers dies apparie la tos era seca sense arrencar res, y apres passat lo sete o quatorze scopien molt del pit, ... y tenien molt gran vigilia per causa de la tos». Por otra parte en esta etapa se superponía el comienzo del período de convalecencia: «tenien una llassitut y desgana de tot lo cors y debilitacio molt gran de virtut y desgana molt gran de menjar qualsevol vianda». En este sentido el gran número de casos, que supusieron el 80-90 \% de la población, no es habitual en una epidemia de gripe aunque, en esta línea, se podría admitir un argumento que es válido para ambos casos: gripe y pertussis, ya que se trataba de una población con carencias de todo tipo.

Asimismo, en dicho Manual ${ }^{26}$ se encuentran referencias a testimonios de médicos que habían observado esta enfermedad en Francia en 1507 y 1510. Es interesante analizar que un contemporáneo de la epidemia de 1580, Guillaume de Baillou (1538-1616), decano de la facultad de medicina de París, fue probablemente el primero en describir la tos ferina en 1578 bajo el nombre de Tussis Quintana, con el siguiente contenido:

26 Manual (1580), p. 248. 
Jam ante de aeftatis initio dictum est:: sub sinem aeftatis ídem fere morbi qui \& antea viguerunt. Aestas sagrans \& aestuosa fuit. Pueros quadrimeftres, decimetres, \& paullo adultiores febres adórate sunt, quae innumeros fuftulerunt: máxime ifta folennis tuffis, quae Quinta feu Quintana vulgo dicitur, de qua ante dietum est. Hujus gravia funt fymptomata: Pulmo ita irritatur, ut omni contentione nitens excutere id quod moleftum est, nec admittat spiritum, nec viviffim facile reddat: intumefcere videtur, \& quasi strangulabundus aeger mediis faucibus haerentes spiritus haber. Cur Quinta vulgo dicatur, dubio non caret. Quidam verbum fictitium effe putant per Onomatopoeiam, Nominis fictionem, ab eo fono \& ftrepitu, quem edunt ita tuffientes: alii non inde repetunt, fed vocari Latine tuffim Quintanam putant quod certis horis repetat: id quod experientia verum probat: nam vacant ifta tuffiendi molestia aliquando horarum quatuor aut quinque fpatio, deinde repetit ifte tuffiendi Paroxysmus, aliquando tam moleftus, ut fanquis \& per nares, \& per os vi excernatur: faepiffime fubverfio ventriculi contingit. Nondum quemque auctorem legi, qui de ea tuffi verba faceret ${ }^{27}$.

La proximidad de esta descripción y la epidemia, nos llama la atención a pesar de que los autores del Manual de Novells Ardits fueran desconocedores de sus trabajos. Lo cual plantea una vez más serias dudas acerca de que este episodio fuera una gripe, dado que distintos autores de la época habían proce-

27 Ya se habló con anterioridad del inicio del verano; al fin de la temporada estival resurgieron casi las mismas enfermedades que también antes del mismo estuvieron en auge. El estío fue ardiente y abrasador. Unas fiebres afectaron a niños de cuatro meses, de diez y un poco más crecidos, fiebres que sometieron a un número incontable; en especial (causó estragos) una severa tos, que vulgarmente se denomina Quinta o Quintana, la cual ya se ha mencionado antes. Sus graves síntomas son los siguientes: el pulmón se irrita de tal modo que, en sus denodados esfuerzos por expulsar el agente causante de la irritación, experimenta una notable dificultad en la alternativa inspiración y expiración del aire (apenas puede inspirar ni expeler a su vez el aire). El enfermo parece hincharse (congestionarse) y, como en los casos de estrangulamiento, el aire queda retenido en medio de la garganta. No se sabe con certeza el por qué de la acepción popular Quinta. Hay quienes piensan que se trata de un nombre figurado por onomatopeya (onomatopeya: figura retórica), por el ruido estrepitoso que emiten los que así tosen. Otros no lo derivan de aquí, más bien opinan que la denominación latina Tos Quintana responde a que el fenómeno se repite a determinadas horas, hecho que la experiencia demuestra como cierto, pues los afectados se ven libres de esta aparatosa tos en algún momento del día, por espacio de cuatro o cinco horas; después se reanuda el acceso de tos (paroxismo), en ocasiones con tanta brusquedad que provoca un violento vómito de sangre por vía nasal y oral; muy a menudo el proceso se ve acompañado de una reversión del ventrículo. Todavía no he leído autor alguno que hiciera mención de esta tos. Traducción realizada por: Xavier Gómez Font y Concepción Ferragut. BAILlou, G. (1772), Medici Parisiensis celeberrimi Opera Omnia. Tomus primus Studio et Opera. M. Jacobí Thevart. Genevae. Apud Frates de Tournes. 
dido a una descripción diferenciada. Contemporánea de esta descripción es la que se puede encontrar en un artículo del periódico Davenport Times de Davenport en Ohio, de fecha 2 de Junio de 1900. En él se puede leer una cita del diario de Pierre de L'Estolla contemporáneo de Enrique III de Francia (1551$1589)^{28}$ :

El Coqueluche en Paris, año 1580 -Desde el dos al ocho de Junio cayeron enfermas en París 10.000 personas de una enfermedad con forma de reuma o catarro, que llamaban 'coqueluche'. Esta enfermedad atacaba con dolor de cabeza, estomago y piernas y lasitud en todo el cuerpo, y continuo en el conjunto del reino de Francia mientras el año no se acabe, así que una vez haya finalizado ninguno en ciudad o casa de pueblo haya escapado.

Por otra parte, la gripe tiene una rápida evolución y no respeta poblaciones, extendiéndose por todo el territorio. En Villalba ${ }^{29}$, nos encontramos los siguientes textos referidos al año 1580: «A 31 de Agosto de 1580 empezo en España la enfermedad contagiosa del catarro, la qual casi despobló a Madrid y otras muchas villas y ciudades». Y «en 1580 hubo la enfermedad del catarro que cundió tanto, que dentro de diez o doce dias enfermaron en la ciudad (Barcelona) mas de veinte mil personas, de que murieron muchos: hallándose anotado que en 7 de Septiembre estaban con esta dolencia todos los vecinos».

Aunque en este texto se habla de que casi se despobló Madrid y otras muchas villas y ciudades, parece ser que su incidencia no fue generalizada en todo el territorio de la Península Ibérica. Los reyes Don Felipe II (1527-1598) y Doña Ana de Austria se infectaron, tal y como se recogió en la Memoria de los primeros frailes que vinieron a fundar este monasterio de Sant Lorenzio el real ${ }^{30}$. El rey estuvo al borde de la muerte, salvándose, suerte que no corrió su esposa Doña Ana de Austria que murió embarazada.

Este hecho lo consideramos de importancia ya que habiéndonos dirigido al Archivo Histórico Municipal de Valencia (AHMV), en el Llibre de Pregons $i$ Rogatives de 1579-1595 encontramos una llamada a la alegría y gracias, por

28 «The Grip», Davenport Times, Ohio (USA), 2 de junio de 1900. URL: http://www. celticcousins.net/scott/grip.htm [21/07/2003].

29 Villalba, J. (1802), Epidemiología española o historia cronológica de las pestes, contagios, epidemias, epizootias que han acaecido en España desde la venida de los cartagineses hasta el año 1801, Madrid, Imprenta de Don Mateo Repullés.

30 En la Colección de Documentos Inéditos para la Historia de España (Codoin), VII, pp. 269. 
la mejora de la salud de su majestad Felipe II, el 20 de agosto de 1580 y posteriormente, para el 3 de octubre de 1580, la organización de una procesión de gracias por la mejora de la enfermedad del rey ${ }^{31}$.

Las noticias corrían en este caso más que la enfermedad, ya que no encontramos en este libro ni en ningún otro, de los que tradicionalmente contienen referencias a las actuaciones del Consell de la ciudad, ningún dato adicional relativo a esta epidemia. Lo cual, por tanto, se podría interpretar como que no hubo ninguna incidencia epidémica, aspecto este que podría ser considerado como un dato más a la hora de sostener las dudas, acerca de que se tratara de una epidemia de gripe, dadas las características que la evolución de la gripe presenta normalmente. Siendo sorprendente, que en el caso de que se tratara auténticamente de gripe y dada la incidencia que esta enfermedad presentaba en el resto de las ciudades afectadas, no se hubiera extendido también a la ciudad de Valencia. Por otra parte, el padecimiento de una epidemia de estas características hubiera dejado un rastro documental importante en las instituciones sanitarias de la época, al igual que ocurrió en otras ciudades europeas, tales como Milán o Roma, cuyos registros hospitalarios fueron estudiados en relación con epidemias de gripe por Lancisi y Gagliardi ${ }^{32}$.

La revisión de los libros de ingreso de enfermos del Hospital General de Valencia $^{33}$ del periodo comprendido entre junio y noviembre de 1580 , tramo que comprende ampliamente el espacio de tiempo de la epidemia de Barcelona, nos impresiona negativamente a la hora de hablar de una gripe. Las cifras de ingresos de enfermos oscilaron desde los 256 de junio a los 261 de noviembre, manteniéndose el resto de los meses dentro de la normalidad: en julio ingresaron 258 enfermos, en agosto 284, en septiembre 283 y 345 en octubre. Este último dato de octubre nos llamó la atención, por lo que procedimos a su desglose, con la intención de descartar la posibilidad de un patrón infeccioso, pero los casos presentaban una evolución anárquica lo que evidenciaba un incremento de la morbilidad sin mantener una estructura regular.

A esto hay que añadir que, en el mes de octubre, la epidemia había cedido en la ciudad de Barcelona, y que la diferencia numérica de enfermos ingresados, con el resto de los meses no era muy importante. En suma, considerando

31 Archivo Histórico Municipal de Valencia, Llibre de Pregons i Rogatives, 1579-1595, 20 de agosto de 1580 y 3 de octubre de 1580.

32 Citado en OlagüE De Ros, G. (1981), «La epidemia europea de gripe de 1708-1709. Difusión témporo-espacial e interpretaciones contemporáneas», Dynamis, 1, 51-86.

33 Archivo Histórico de la Diputación de Valencia: IV enfermos. IV.2 Ingresos, estancias y altas, 1580 . 
los ejemplos anteriormente comentados de Roma y Milán, los incrementos de ingresos hospitalarios y la alta mortalidad padecida, nos permite descartar que se tratara de un proceso similar en el área de Valencia. Más aún por cuanto, ya en 1826, Jones un médico americano escribió ${ }^{34}$ :

el simple hecho es... que esta epidemia de [gripe] afecta al conjunto de la región en el espacio de una semana; y mucho más que esto, al conjunto de un continente tan extenso como Norteamérica... en el plazo de una pocas semanas.

Volviendo a la ciudad de Barcelona, cada enfermo sanaba según su constitución, fallecían con más facilidad los que «tenien los pits guastats y vells, y molts xics de llet y moltes dones prenyades» (Manual de Novells Ardits, 1580), los pequeños morían por falta de leche, los viejos por no tener fuerza para expectorar y las mujeres embarazadas porque al hacer fuerza para toser abortaban. El padre Pere Gil hace referencias a similares condiciones ${ }^{35}$ :

Moriren molts infants, y moltas personas vellas, y debils, y enfermisas. Y las personas que actualment estavan malaltas, sobrevenint los dit catarro casi totas moriren. Succey en Barcelona; que per espay de quinze ò vint dias: apenas se pogueren fer sermons, ni cantar los officis, en las Parrochias, y enlos Monestirs; ni dirse missas bayxas sino molt poques. Posaren li en aquest any molts noms, perque lo nomenaren, lo any de la Temporada, y lo any del moquillo: y en Italia.....(blanco). Per lo propi nom fou: Lo any .1580. del gran y universal catharro.

E incluye aspectos tales como las dificultades que esta epidemia conllevó para la realización de actos públicos y una referencia específica a los distintos nombres que recibió la epidemia. Por último es de destacar la capacidad de observación de Pere Gil, que incluye en su escrito una referencia a la mortalidad avícola en la ciudad de Barcelona: «me certificaren molts, que casi tots los ossells de gabia de Barcelona moriren. Pardals ni ossells no volaren tot aquell temps ni enla ciutat ni enlo pla de Barcelona». Aspecto éste que puede ser atribuido a ambas patologías, gripe y pertussis, ya que, como en muchas otras enfermedades infecciosas respiratorias, lo pájaros y los humanos somos susceptibles de contraer la infección.

34 JONES, A. (1826), «Observations on the Influenza or Epidemic Catarrh, as it Prevailed in Georgia during the Winter and Spring of 1826», Philadelphia Journal of Medical Physical Sciences, 13, 1-30, p. 5.

35 IGLESIES (1949). 
El tratamiento proporcionado, por los médicos en este tiempo, tal y como viene descrito por Pere Gil - «curayanlo los metges ab sola dieta, sens sagnia; y la dieta no era molta: y donavan bons aliments de caldos sustanciosos, y medicaments per ablanir y arrancar» ${ }^{36}$ - y por Desplau — «la cura feren los metges en dit malson molta dieta y ayunes. los qui foren segnats sen moriren molts $\rangle^{37}$ - , se componía única y exclusivamente de una dieta reducida, combinada en algún caso con ayunas.

Aparentemente, la sangría no estaba recomendada en estos casos, a los cuales posiblemente se les administraba algunas sustancias que tenían efecto emoliente, favoreciendo y suavizando la expectoración. Coincidían los galenos catalanes con los franceses en el tratamiento ya que en el diario de Pierre de L'Estolla citado anteriormente, también se podía encontrar una referencia al tratamiento que se aplicaba para esta alteración en la ciudad de París:

El mejor remedio que han encontrado los médicos es hacer que el enfermo se abstenga de tomar vino. A algunos de ellos se les ordena sangrías y ruibarbos a otros tapioca y finalmente encontraron lo mejor, mantener al enfermo en la cama y permitirles comer y beber poco.

\section{CONCLUSIÓN}

A partir del análisis de los testimonios encontrados, defendemos la hipótesis de que el episodio del Gran Catharro de 1580 podría tratarse de un brote epidémico de tos ferina. Los datos obtenidos suscitan suficientes dudas respecto a que se trate de una epidemia de gripe y apoyan de una manera más decidida la posibilidad de que se tratara de una epidemia de tos ferina. Aunque todo ello debe entenderse con la cautela que el tiempo transcurrido impone y la necesidad de continuar profundizando en la búsqueda de testimonios que permitan una mejor aproximación al evento.

\footnotetext{
36 IgLeSIES (1949).

37 Despalau (1580).
} 